\title{
EFFECTS OF CLIMATE CHANGE AND DROUGHT IN KONYA: A REVIEV
}

\author{
Sukru DURSUN \\ Konya Technical University, Faculty of Engineering and Natural Sciences, \\ Environmental Engineering Department, Konya, Turkey; \\ *Corresponding Author Sukru Dursun, e-mail address: sdursun@ktun.edu.tr;
}

Received July 2020; Accepted August 2020; Published September 2020;

DOI: https://doi.org/10.31407/ijees10.403

\begin{abstract}
The environment of our planet likes simply like a greenhouse. Practically $50 \%$ of the sun's lights arriving at the earth are reflected from the earth. Atmospheric climate is described via carbon dioxide, methane, water stream, ozone, nitrogen oxides, and so others, which are additionally called ozone depleting substances. On these gases, they reflect a portion of the sun beams reflected from the earth back to the earth. The effect of environmental change isn't only an expansion in temperatures. Plants, creatures and biological systems just as human networks are at genuine hazard because of components, for example, dry season, floods, serious tropical storms, expanded recurrence and impact of extraordinary climate occasions, raised sea and ocean water levels, expanded causticity of the seas, softening icy masses. An impermanent dampness lop-sidedness is called dry season territorially. Its long-haul indication permits time to take the fundamental measures for dry season, however dry spell is the most noticeably terrible calamity after some time. The drought, which can manifest itself everywhere after the moisture balance deteriorates, can be felt even in areas with high precipitation. Drought has been effective in Iran as in many countries around the world and the duration of drought has been constantly increasing in the last 20 years. As a result of the study, it was determined that the yield of dry products will decrease in the future. As a precaution, it is recommended to complete the dams and ponds, transfer water between the basins and switch to modern irrigation systems. Drought has a complex structure that affects many sectors of the economy and extends this effect far beyond regions with drought. The reason for this is that water is an indispensable factor in production. The majority of the Konya Closed Basin water supply is supplied from groundwater due to the low level of above-ground water sources, limited alternative irrigation sources or full efficiency. Konya Closed Basin has significant water potential. However, the increasing agricultural activities in recent years have caused excessive and unplanned water use, and thus the surface and groundwater levels have decreased.
\end{abstract}

Keywords: Climate change, Greenhouse effect, Drought, Temperature increase, precipitation 